\title{
Entire lacrimal sac within the ethmoid sinus: outcomes of powered endoscopic dacryocystorhinostomy
}

This article was published in the following Dove Press journal:

Clinical Ophthalmology

5 July 2016

Number of times this article has been viewed

\author{
Mohammad Javed Ali \\ Swati Singh \\ Milind N Naik \\ Institute of Dacryology, \\ LV Prasad Eye Institute, \\ Hyderabad, India
}

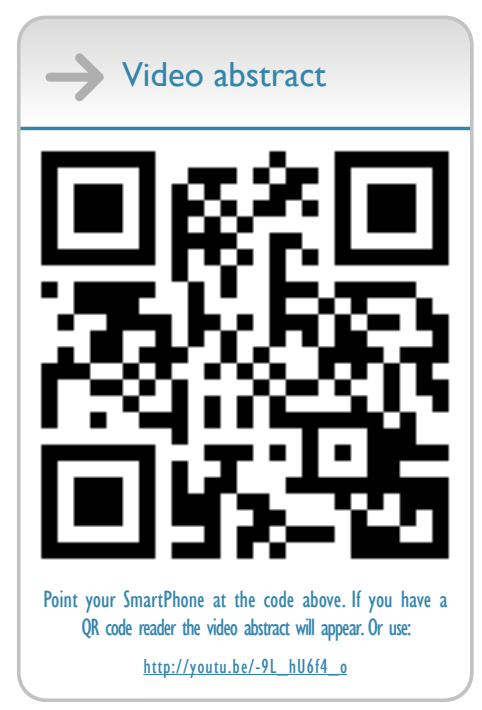

Correspondence: Mohammad Javed Ali Institute of Dacryology, LV Prasad Eye Institute, Banjara Hills, Hyderabad,

Telangana 500034, India

Email alkispsaltis@gmail.com
Background: The aim of this study was to report the outcomes of powered endoscopic dacryocystorhinostomy (PEnDCR) in patients with lacrimal sac within the sinus.

Materials and methods: Retrospective analysis was performed on all patients who underwent PEnDCR and were intraoperatively documented to have complete lacrimal sac in sinus. Data collected included demographics, clinical presentations, associated lacrimal and nasal anomalies, intraoperative findings, intraoperative guidance, complications, postoperative ostium behavior, and anatomical and functional success. A minimum follow-up of 6 months postsurgery was considered for final analysis.

Results: A total of 17 eyes of 15 patients underwent PEnDCR using standard protocols, but with additional intraoperative guidance where required and careful maneuvering in the ethmoid sinus. The mean age of the patients was 37.2 (range 17-60) years. Of the unilateral cases, $69 \%$ (nine of 13) showed left-side predisposition; $80 \%$ of patients showed regurgitation on pressure over the lacrimal sac area. Associated lacrimal and nasal anomalies were observed in $13.3 \%$ (two of 15) and 40\% (six of 15), respectively. At a mean follow-up of 6.6 months, anatomical and functional success were observed in $93.3 \%$ (14 of 15). One patient showed failure secondary to cicatricial closure of the ostium.

Conclusion: An entire sac within an ethmoid sinus poses a surgical challenge. Good sinussurgery training, thorough knowledge of endoscopic anatomy, careful maneuvering, and use of intraoperative navigation guidance result in good outcomes with PEnDCR.

Keywords: lacrimal sac, ethmoid sinus, endoscopic, DCR

\section{Introduction}

Paranasal sinuses have an intricate relationship with the ocular adnexa and orbit. ${ }^{1-3}$ The bony lacrimal fossa (LF) and lacrimal drainage system are closely related anatomically to the ethmoid sinuses. ${ }^{1-4}$ The ethmoid air cells develop after birth, become radiologically recognizable by age 2 years, and attain adult dimensions by 12 years of age. ${ }^{1,2}$ There is a well-known anatomical relationship between the fundus of the lacrimal sac and agger nasi, which is a part of the anterior ethmoid air cells (AEACs).,5 Numerous papers have reported contiguous pathologies involving the lacrimal drainage system and the sinuses. ${ }^{7-11}$ However, very few have specifically studied the relationship of sinuses, specifically EACs, with the LF, ${ }^{12,13}$ and its subsequent influence on dacryocystorhinostomy (DCR). ${ }^{14-19}$

The anatomical relationship between the bony LF and the AEACs is categorized into three types. ${ }^{15}$ In category I, sinuses are behind the posterior lacrimal crest, in category II, the AEACs are in front of the posterior lacrimal crest but behind the suture 
at the anterior edge of the lacrimal bone, and in category III, the sinuses extend into the frontal process of the maxilla, anterior to the lacrimal bone suture. The authors of the present study report their experience of performing powered endoscopic DCR (PEnDCR) in cases where the entire lacrimal sac is within the boundaries of the ethmoid sinus.

\section{Materials and methods}

LV Prasad Eye Institute Institutional Review Board approval was obtained. However, patient consent was not deemed necessary by the Institutional Review Board due to the retrospective nature of the study. Retrospective analysis was performed on all patients who had undergone a PEnDCR in 2014 and 2015 and were documented to have the entire lacrimal sac within the boundaries of the ethmoid sinus. All surgeries were performed by a single surgeon (MJA) as per a standard protocol published earlier, ${ }^{6,20}$ with modifications specific to the sac in sinus. Data collected include demographics, clinical presentations, associated lacrimal and nasal anomalies, intraoperative findings, intraoperative guidance, complications, postoperative ostium behavior, and anatomical and functional success. A minimum follow-up of 6 months postsurgery was considered for analysis.

\section{Diagnosis}

A lacrimal sac can be labeled a "complete sac in sinus" when it lies in its entirety within the boundaries of the sinuses, mostly the ethmoid (Figure $1 \mathrm{~A}-\mathrm{C}$ ). The definitive diagnosis of such a sac in the sinus is established intraoperatively; however, preoperative examination may provide a few clues that may be suggestive of at-risk patients. The authors observed that their cohort had patients with steep nasal bridges, deeply set eyes, and posterior insertion of medial canthal tendons. However, a large series is required to confirm this association. Intraoperatively, a flatter frontal process of the maxilla along with middle turbinate malpositions may provide useful clues (Figure 1A and B). Intraoperative guidance in the form of image guidance or transcanalicular light source was helpful in delineating the entire anteroposterior and superoinferior extent of the lacrimal sac within the ethmoid sinus (Figure 1D-F). Occasionally, the lacrimal sac may be found superoposteriorly in close relation to the frontal recess and frontal sinus-outflow pathways (Figure 2A and B). This has been observed more commonly following trauma. ${ }^{17}$

\section{Surgical technique}

The surgical principles of PEnDCR remain the same in these cases; ${ }^{6,20}$ however, uncinectomy is needed to gain access to the ethmoids, and care should be taken to remove the EACs and mucosa in front of the lacrimal sac. The mucosa of the ethmoid sinus is thin, friable, and whiter compared to the nasal mucosa. The ethmoidal bones are thin and egg shell-like and lined by the ethmoid mucosa. Bony ethmoid wall lateral to the sac should be carefully preserved to avoid violations of lamina papyracea and orbital tissues. The lateral ethmoidal wall mucosa should be preserved for use as a mucosa-mucosa approximation with the marsupialized lacrimal sac flaps. Since most of the surgical intervention happens within the ethmoid sinus, it is important to be aware of ethmoidal vessels and avoid injury to them. If the sac malposition is superoposterior, it is of utmost importance to preserve the frontal recess anatomy and avoid injuries to frontal sinus-drainage pathways. Occasionally, a partial middle turbinoplasty may be desired to gain wider access to deeper-situated lacrimal sacs. All patients in the current cohort underwent intubation and mitomycin C (0.02\% for 3 minutes) as described earlier. ${ }^{20,21}$ Stents were retained for 4 weeks. Postoperatively, these patients required more frequent saline nasal douching (thrice a day) and weekly crust cleaning (for 4 weeks) compared to regular EnDCR. It is important for the surgeon to be aware of the pseudocicatrix phenomenon ${ }^{22}$ observed in sac-in-sinus syndrome on postoperative endoscopic examination. The term "ostium pseudocicatrix" is used when the deeply located ostium is partly covered anteriorly by a minimally mobile scar tissue like a curtain, behind and lateral to which is the usual location of the ostium (Figure $2 \mathrm{C}$ and D). Postoperative endoscopic ostium evaluation can be difficult, because of its deeper location and the pseudocicatrix phenomenon, and hence needs careful endoscopic maneuvering with a $2.7 \mathrm{~mm}$ telescope to minimize discomfort to the patient.

\section{Results}

A total of 17 eyes of 15 patients underwent PEnDCR using standard protocols, but with additional intraoperative guidance where required and careful maneuvering in the ethmoid sinus. The mean age of the patients was 37.2 (range 17-60) years. Unilateral cases accounted for $86.6 \%$ (13 of 15). Of the unilateral cases, $69 \%$ (nine of 13 ) showed left-side predisposition. There was no gross sex predisposition, with females accounting for $53.3 \%$ (eight of 15 ) of the patients. A history of acute dacryocystitis was observed in $26.6 \%$ (four of 15) patients. Of the 15 patients, 12 were diagnosed with primary acquired nasolacrimal duct obstruction, two had failed EnDCR, and one had a traumatic secondarily acquired nasolacrimal duct obstruction. Epiphora was a common complaint, with $80 \%$ of patients showing regurgitation on pressure over the lacrimal sac area. Associated lacrimal anomalies were observed in $13.3 \%$ (two of 15 ) of patients, and included one patient each 

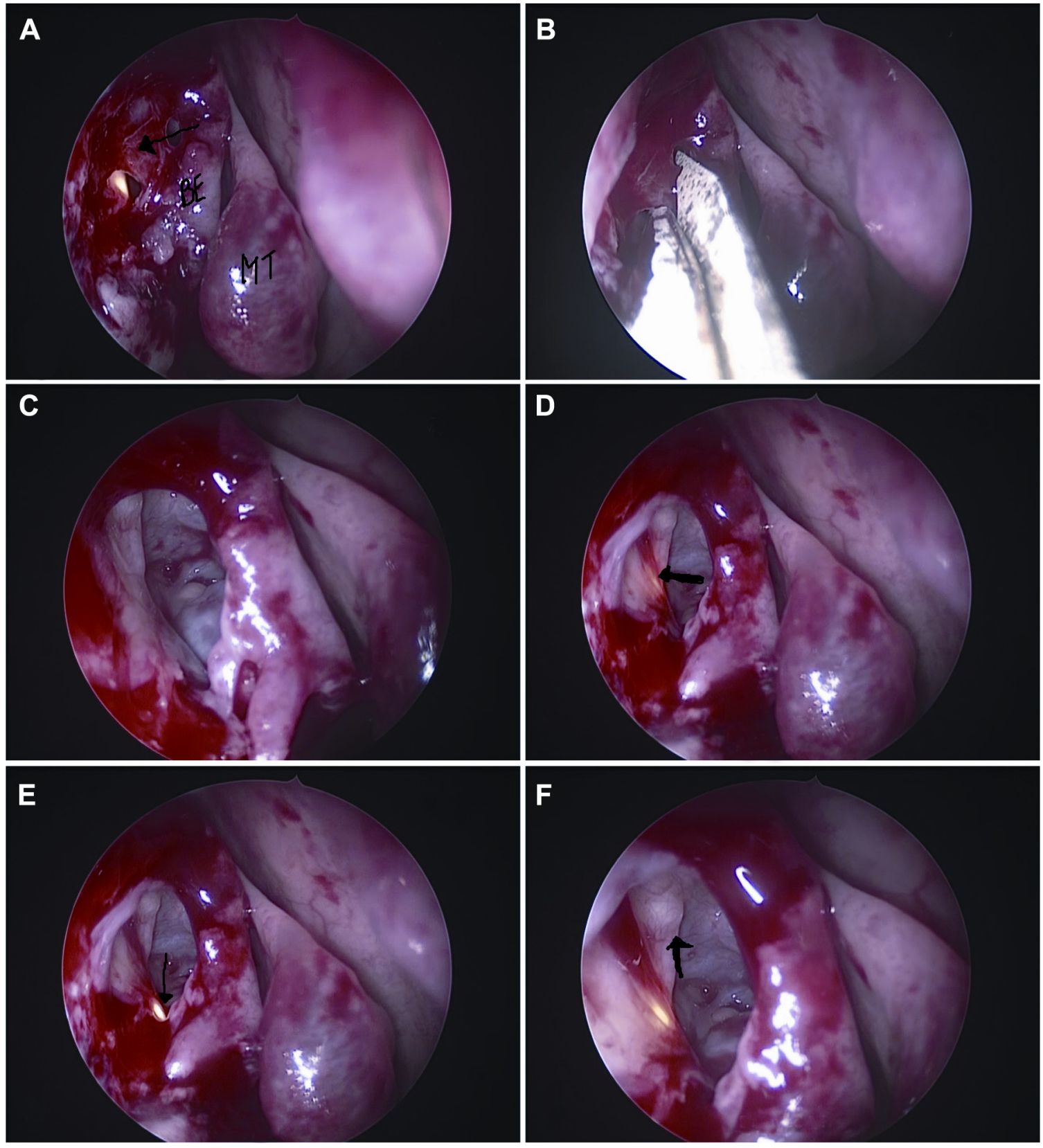

Figure I Endoscopic views of the right nasal cavity.

Notes: Partly opened anterior mucosa of the bulla ethmoidalis (arrow) (A). Note the location of the bulla ethmoidalis and middle turbinate. Anterior mucosa of the ethmoid being incised following removal of anterior ethmoid air cells (B). Completely exposed ethmoid sinus (C). Light-probe guidance showing the lacrimal sac (arrow) (D) and nasolacrimal duct (arrow) (E). Close-up view showing the entire lacrimal sac within the ethmoid sinus (F). Note the medial wall of the orbit (arrow).

Abbreviations: BE, bulla ethmoidalis; MT, middle turbinate.

with single punctal agenesis and lower punctal single canalicular wall aplasia. Nasal anomalies were observed in $40 \%$ (six of 15) of patients, and included middle turbinate malpositions and flat frontal process of maxilla in three patients each. Adjunctive procedures performed were septoplasty in $13.3 \%$ (two of 15) and partial middle turbinoplasty in 6.6\% (one of 15 ) of patients. Intraoperative complications included moderate bleeding in one case and irregular sac flaps in another case. Postoperative endoscopic evaluation showed most patients universally demonstrated very deeply situated ostium, with pseudocicatrix being observed in 53.3\% (eight of 15). At a mean follow-up of 6.6 months, anatomical and functional success was observed in $93.3 \%$ (14 of 15). One patient showed failure secondary to complete cicatricial closure of the ostium and was a revision case. A re-revision was advised, but the patient refused any further interventions.

\section{Discussion}

The current study examined the outcomes of PEnDCR in the setting of the entire lacrimal sac within the ethmoid sinus. 

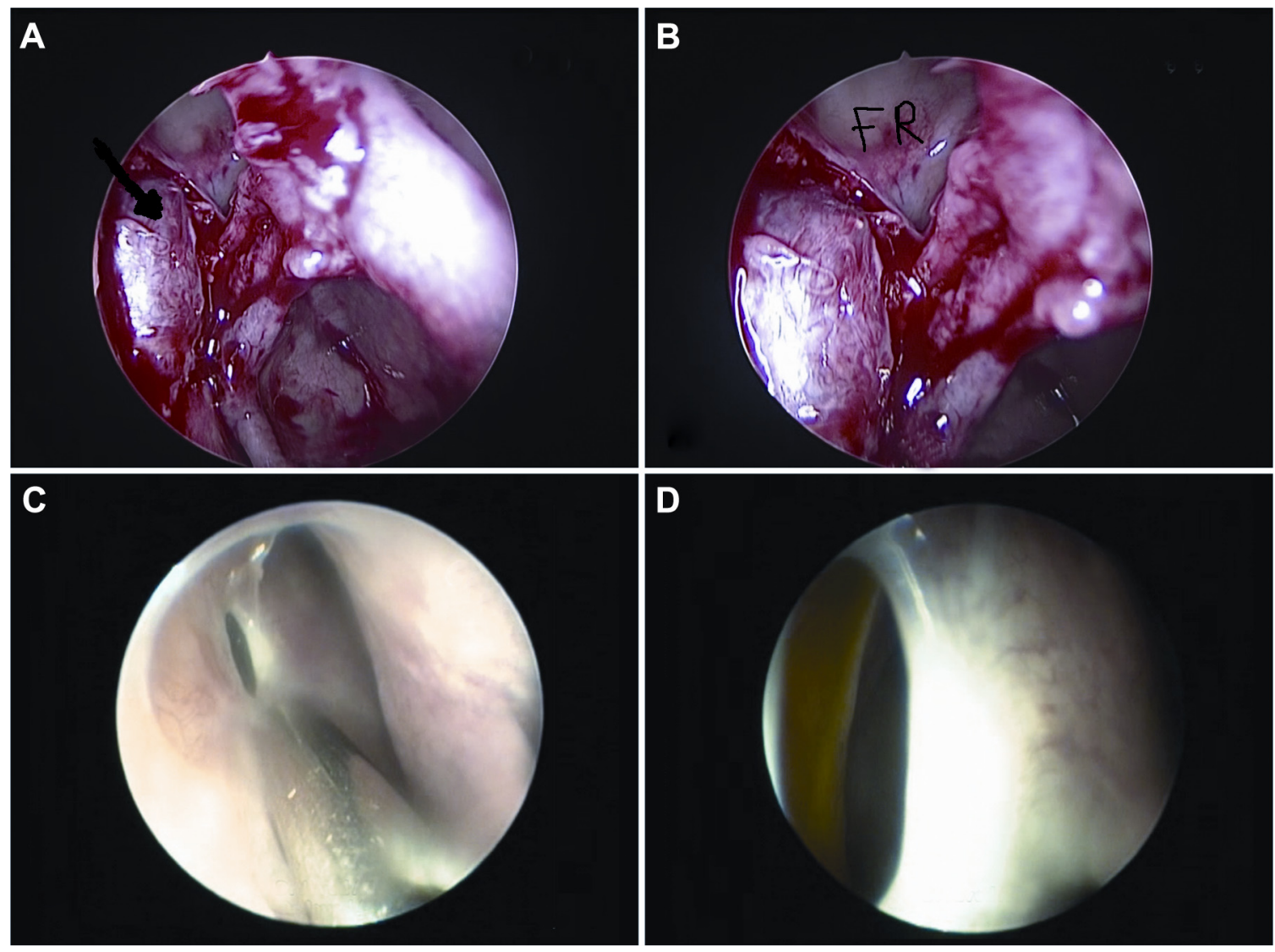

Figure 2 Endoscopic view of the right nasal cavity.

Notes: Lacrimal sac (arrow) in close vicinity of the frontal sinus recess (A). Close-up view showing the recess more clearly (B). Postoperative endoscopic view showing the pseudocicatrix (shown by the probe) all around with a small window $(\mathbf{C})$. Close-up view through the window demonstrates a posterior and lateral ostium with positive fluorescein endoscopic dye test (D).

Abbreviation: FR, frontal sinus recess.

Left-side involvement and positive regurgitation on lacrimal sac compression were very common. All patients except one had successful outcomes. Preoperative planning, intraoperative navigation where needed, and a good knowledge of endoscopic sinus anatomy helps in avoiding complications and performing the surgery safely.

Ethmoid sinuses are usually divided into three groups of cells; anterior, middle, and posterior. Although the anatomical relationship between the LF and ethmoid is definitive, it may show variations and may even be asymmetrical. ${ }^{1-4,14,15}$ Jiang et $\mathrm{al}^{12}$ studied AEACs in 16 adult cadavers, and found that categories II and III were common, accounting for $50 \%$ and $31.2 \%$, respectively. Blaylock et al ${ }^{15}$ studied computed tomography scans of 190 orbits with normal ethmoid anatomy, and found that in $93 \%$ of the orbits, the AEACs extended anteriorly to the posterior lacrimal crest, with $40 \%$ entering the frontal process of the maxilla. They recommended initial entry into the ethmoid sinus during external DCR to avoid injury to the nasal mucosa. Talks and Hopkisson ${ }^{14}$ studied the frequency of ethmoid-cell entry while performing an external DCR, and found that it commonly happened $(46 \%, 23$ of 50$)$ via the suture in the medial wall of the LF. Contrary to what Blaylock et al ${ }^{15}$ presented, Talks and Hopkisson ${ }^{14}$ believed that initial entry into the ethmoid could be a trap, and if not recognized may lead to a blind cul-de-sac in the form of ethmoid sinus and lead to failure of surgery. They also suggested possibilities of suturing lacrimal sac flaps to the ethmoid mucosa without any entry into the nasal cavity. Similar apprehensions were put forward by Welham and Wulc, ${ }^{19}$ who noticed that in the presence of adjacent EACs, the subsequent scarring of these cells may lead to an increase in complications and failures of DCR. The authors of the current series believe that these apprehensions may not be applicable to an EnDCR, since the nasal mucosa is fashioned first and it is very easy to identify the ethmoid structures and its mucosa. The current study had good successful outcomes with PEnDCR, even though it included only cases where the entire lacrimal sac was within the sinus and not regular cases where the LF was adjacent to AEACs. The advances in endoscopic surgeries coupled 
with intraoperative guidance have significantly improved the surgeon's ability to deal with lacrimal sacs within the ethmoid sinuses.

\section{Conclusion}

PEnDCR offers good results in the setting of a sac in the sinus. Further studies with large sample size with preoperative imaging and intraoperative stereotactic guidance may be helpful in formulating better diagnostic and management guidelines.

\section{Disclosure}

Mohammad Javed Ali receives royalties from Springer for his textbook Principles and Practice of Lacrimal Surgery. The other authors report no conflicts of interest in this work.

\section{References}

1. Hengerer AS. Surgical anatomy of the paranasal sinuses. Ear Nose Throat J. 1984;63:137-143.

2. Miller AJ, Amedee RG. Functional anatomy of the paranasal sinuses. J LA State Med Soc. 1997;149:85-90.

3. Terrier F, Weber W, Ruefennacht D, Porcellini B. Anatomy of the ethmoid: CT, endoscopic and macroscopic. Am J Radiol. 1985;144:493-495.

4. Whitnall SE. The relations of the lacrimal fossa to the ethmoid cells. Ophthalmic Rev. 1911;30:321-325.

5. Wormald PJ, Kew J, Van Hasselt CA. The intranasal anatomy of the nasolacrimal sac in endoscopic dacryocystorhinostomy. Otolaryngol Head Neck Surg. 2000;123:307-310.

6. Ali MJ, Psaltis AJ, Bassiouni A, Wormald PJ. Long-term outcomes in primary powered endoscopic dacryocystorhinostomy. Br JOphthalmol. 2014;98:1678-1680.

7. Zodpe P, Chung SW, Kang HJ, Lee SH, Lee HM. Endoscopic treatment of nasolacrimal sac obstruction secondary to fibrous dysplasia of paranasal sinuses. Eur Arch Otorhinolaryngol. 2007;264:495-498.

8. Facer ML, Ponikau JU, Sherris DA. Eosinophilic fungal rhinosinusitis of the lacrimal sac. Laryngoscope. 2003;113:210-214.
9. Perry LJ, Jakobiec FA, Zakka FR, Rubin PA. Giant dacryocystomucopyocele in an adult: a review of lacrimal sac enlargements with clinical and histopathologic differential diagnoses. Surv Ophthalmol. 2012; 57:474-485.

10. Remulla HD, Rubin PA, Shore JW, Cunnigham MJ. Pseudodacryocystitis arising from anterior ethmoiditis. Ophthal Plast Reconstr Surg. 1995; $11: 165-168$

11. Glatt HJ. Evaluation of lacrimal obstruction secondary to facial fractures using computed tomography or computed tomographic dacryocystography. Ophthal Plast Reconstr Surg. 1996;12:284-293.

12. Jiang M, Zhang S, Li Z, Li Z, Zhou S, Ji R. [Applied anatomy of anterior ethmoid relevant to endoscopic transnasal dacryocystorhinostomy]. Lin Chuang Er Bi Yan Hou Ke Za Zhi. 1999;13:497-498. Chinese.

13. Ali MJ, Murphy J, Wormald PJ, Psaltis AJ. Bony nasolacrimal duct dehiscence in functional endoscopic sinus surgery: radiological study and discussion of surgical implications. J Laryngol Otol. 2015;129 Suppl 3: S35-S40.

14. Talks SJ, Hopkisson B. The frequency of entry into an ethmoidal sinus when performing a dacryocystorhinostomy. Eye (Lond). 1996;10: $742-743$.

15. Blaylock WK, Moore CA, Linberg JV. Anterior ethmoidal anatomy facilitates dacryocystorhinostomy. Arch Ophthalmol. 1990;108: 1774-1777.

16. Wilson WR, Grove AS. A method for combined dacryocystorhinostomy with external ethmoidectomy. Head Neck Surg. 1981;4:9-12.

17. Ali MJ, Naik MN. Image-guided dacryolocalization (IGDL) in traumatic secondary acquired lacrimal duct obstructions (SALDO). Ophthal Plast Reconstr Surg. 2015;31:406-409.

18. Shams PN, Selva D. Traumatic sinolacrimocutaneous fistula managed with endonasal dacryocystorhinostomy and anterior ethmoidectomy. Arch Ophthalmol. 2012;130:1311-1313.

19. Welham RA, Wulc AE. Management of unsuccessful lacrimal surgery. Br J Ophthalmol. 1987;71:152-157.

20. Ali MJ, Psaltis AJ, Wormald PJ. Long-term outcomes in revision powered endoscopic dacryocystorhinostomy. Int Forum Allergy Rhinol. 2014;4:1016-1019.

21. Chisty N, Singh M, Ali MJ, Naik MN. Long-term outcomes of powered endoscopic dacryocystorhinostomy in acute dacryocystitis. Laryngoscope. 2016;126:551-553.

22. Ali MJ, Psaltis AJ, Wormald PJ. Dacryocystorhinostomy ostium: parameters to evaluate and DCR ostium scoring. Clin Ophthalmol. 2013 $8: 2491-2499$.
Clinical Ophthalmology

\section{Publish your work in this journal}

Clinical Ophthalmology is an international, peer-reviewed journal covering all subspecialties within ophthalmology. Key topics include: Optometry; Visual science; Pharmacology and drug therapy in eye diseases; Basic Sciences; Primary and Secondary eye care; Patient Safety and Quality of Care Improvements. This journal is indexed on Submit your manuscript here: http://www.dovepress.com/clinical-ophthalmology-journal

\section{Dovepress}

PubMed Central and CAS, and is the official journal of The Society of Clinical Ophthalmology (SCO). The manuscript management system is completely online and includes a very quick and fair peer-review system, which is all easy to use. Visit http://www.dovepress.com/ testimonials.php to read real quotes from published authors. 